\title{
Prescribing and facilitating withdrawal from benzodiazepines in primary health care
}

Joana Oliveira, ${ }^{1-2}$ Inês Neves, ${ }^{1}$ Milene Fernandes, ${ }^{1}$ Osvaldo Santos, ${ }^{1,3}$ Vasco Maria ${ }^{1-2}$

\begin{abstract}
The chronic use of benzodiazepine anxiolytics and hypnotics is a controversial issue and it is envisaged by most family physicians as a health problem.

Objectives: To summarize benzodiazepine indications, adverse effects, and risks associated with overuse. Available strategies to discontinue these drugs at primary care setting are also explored.

Methods: Literature review included structured searches of MEDLINE and other publications on the subject of treatment with benzodiazepines, their overuse and withdrawal protocols suitable for community settings.

Results and conclusions: Although the national and international recommendations agree on indications and adverse effects of chronic use of benzodiazepines, their overuse has been a clinical concern in Portugal. Benzodiazepines main indications are anxiety and insomnia, when the disorder is severe, disabling or subjecting the individual to extreme distress. However, treatment should be as short as possible, not exceeding eight to twelve weeks for anxiety or four weeks for insomnia. The evidence shows that systematic approaches with brief interventions and recommendation for gradual dose reduction of benzodiazepines seem to have good results among benzodiazepines users. This review is the first step of the development, implementation and effectiveness evaluation of a novel benzodiazepine withdrawal program, to be conducted by family doctors.
\end{abstract}

Keywords: Benzodiazepines; Withdrawal; Adverse effects; Primary care.

\section{INTRODUCTION}

$\Lambda$ ccording to the World Mental Health Survey Initiative, being younger, unemployed or disabled, with no education or incomplete primary studies, living in urban settings, and in Northern Ireland, Portugal or Belgium were associated with an augmented prevalence of mental disorders. Portugal is one of the countries with the highest risk for mood disorders, anxiety disorders, and for any 12month mental disorder. ${ }^{1}$ Psychiatric diseases affect more than a fifth of the Portuguese population, with a high prevalence of depression followed by anxiety syndromes. ${ }^{2-3}$ Considering this high prevalence and the di-

1. Instituto de Medicina Preventiva e Saúde Pública, Faculdade de Medicina, Universidade de Lisboa.

2. Administração Regional de Saúde de Lisboa e Vale do Tejo.

3. Instituto de Saúde Ambiental, Faculdade de Medicina, Universidade de Lisboa. sability associated with these conditions, it is not surprising that mental health is now recognized as a priority in terms of public health programs. ${ }^{2}$ Furthermore, the increase of reported mental illnesses at the primary care level may be related to an increase in the number of patients seeking help due to depressive and anxious disturbances. ${ }^{2}$

Alongside with the high prevalence of anxiety syndromes, Portugal has one of the highest prescription rates of benzodiazepines (BZD) in Europe, which may also point to longer treatment duration and overprescription. ${ }^{4}$ Anxiolytics, sedatives and hypnotics was the most prescribed psychotropic drug group until 2012, for Portugal. There has been a relative increase of anxiolytics and a decrease of hypnotics' prescription. Recent reports also show that BZD are responsible for $7 \%$ of the drug market share in Portugal. ${ }^{4}$ The most pres- 
cribed anxiolytics were alprazolam and lorazepam., ${ }^{2,4}$

A Portuguese study from 2004 showed that the annual prevalence of BZD use among a population served by one health center in the North region was $14.8 \%$ and that the number of patients seeking medical attention and taking BZD was threefold that of non-users. ${ }^{5}$ Another Portuguese study reported that up to $23 \%$ of adult patients registered and consulted within a period of 12 months at a Health Center in the Lisbon periphery were taking BZD. ${ }^{6}$ At the primary care level, a study revealed some heterogeneity of criteria used to support the decision of when and which BZD should be prescribed. ${ }^{7}$

A narrative review was conducted and the most relevant information about BZD indications, adverse effects, and risks of overprescription/overuse are reported in this paper. In addition, the most relevant approaches to support BZD withdrawal at the primary care level are also explored. This review is part of a novel program aimed at helping family doctors in Portugal to prevent BZD inadequate use and to support patients to cease its consumption.

\section{METHODS}

A literature review was conducted on sources of scientific peer-reviewed articles, textbooks and health organizations' reports and recommendations. For the comprehensive assessment of the relevant articles, we privileged original research in outpatient clinics or community settings, independently rated as high-quality studies, reviews or guidelines. The search had no temporal limit. We searched for documental and electronic data sources, including a structured search of MEDLINE, using the following Medical Subject Headings (MeSH) terms: benzodiazepines, withdrawal, adverse effects, and primary care. The review was restricted to papers published in English, Spanish, or Portuguese.

\section{RESULTS}

\section{General principles for BZD prescription}

BZD have six main properties and clinical relevant actions: anxiolytic, hypnotic, anticonvulsant, muscle relaxant, anterograde and retrograde amnesia and alcohol withdrawal. ${ }^{8}$ Their approved indications for the anxiolytic and hypnotic effects are reflected in the recommendations from several health authorities, like the British National Health Service (NHS) or the Portuguese Directorate-General of Health (DGS):-10

- BZD are indicated in anxiety and insomnia when the disorder is severe, disabling or subjecting the individual to extreme distress.

- Treatment should start with the lowest recommended dose in order to prevent dependence, and when a prescription decision is taken, it is recommended to monitor treatment every two weeks.

- Duration of BZD use should be as short as possible, not exceeding eight to 12 weeks for anxiety or four weeks for insomnia. This time period should include tapering off process.

- If the extension beyond the maximum treatment period is necessary, the patient should be evaluated and specialized advice may be necessary.

- The patient must be informed about the short-term duration of therapy and should be instructed about the most adequate tapering off process. Patients must be aware of the rebound phenomena, in order to minimize anxiety symptoms during dose reduction period.

Psychotherapy is recommended as the first approach to anxiety symptoms, ultimately associated or not with psychotropic drugs. In cases of anxiety with depression, it is recommended to prescribe antidepressants as firstline treatment. A BZD for a period up to three or four weeks may be necessary. Antidepressants are usually not associated with significant tolerance or dependence. ${ }^{11}$

Table 2 presents the main contraindications to be considered when prescribing a BZD.

\section{Problems associated with BZD use}

Table 3 summarizes some of the problems associated with BZD consumption. Adverse consequences of BZD are usually dose-related and predictable. More serious adverse effects can result from long-term regular use in therapeutic dosage and from self-prescription or recreational use in excessive doses. ${ }^{12}$

Anterograde amnesia occurs a few hours after administration, especially with hypnotics at higher doses. For this reason, it should be recommended a continuous sleep of seven to eight hours after the intake. It remains unclear whether the usage of BZD induces cognitive impairment after discontinuation, especially in the elderly. ${ }^{13}$ Some studies have shown a positive asso- 
TABLE I. CME objectives and key summary points

Continuing medical education (CME) objectives:

- To alert the health community on the evidence about BZD overuse/misuse and its risks.

- To improve medical literacy regarding BZD indications, its adverse effects, and risks of over-prescription, including long-term use.

- To explore available approaches to discontinue BZD at the primary care level.

Key summary points:

- BZD may have a role as anxiolytics and hypnotics when the disorder is severe, disabling or subjecting the individual to extreme distress. Treatment should be as short as possible, not exceeding eight to 12 weeks for anxiety or four weeks for insomnia, including a tapering off process.

- It is mandatory that the deleterious effects of BZD' long-term use are detected and addressed as a way to prevent dependence and withdrawal syndrome.

- Awareness and motivation of both doctors and patients is the first step for reducing BZD' adverse effects.

- The most important measure for the prevention of inappropriate prescription is the motivation for discontinuing therapy and its supervision.

TABLE II. Main contraindications regarding BZD prescription $^{9}$

\begin{tabular}{l|l} 
Main & $\begin{array}{l}\text { - Myasthenia gravis } \\
\text { contraindications }\end{array}$ \\
- Severe respiratory insufficiency \\
- Sleep apnea syndrome \\
- Severe hepatic insufficiency (due to \\
increased risk of encephalopathy)
\end{tabular}

ciation between BZD and Alzheimer's disease, especially for long-acting substances and when higher doses are used. Although this is still controversial, some authors suggest that BZD use can be an early marker of dementia. ${ }^{14-15}$

Exposure during fetal life has been suggested to contribute to neonatal morbidity and some congenital malformations like orofacial clefts, preterm birth, and low birth weight. The majority of congenital malformations are moderately increased in infants exposed in early pregnancy. ${ }^{13}$ When used in the late phase of pregnancy, or during labor at high doses, effects on the neonate, such as hypothermia, hypotonia or moderate respiratory depression, can be expected. ${ }^{8}$ Some may also develop physical dependence and may be at risk for withdrawal symptoms in the postnatal period up to one-month post-delivery, as well as a possible longterm impact on neurodevelopment. ${ }^{8}$
Some loss of efficacy of BZD may develop after repeated use. The rate of development of tolerance may vary for different drug effects, can develop at different speeds, and can vary between individuals. Prescribing for people who are using high doses and those who use illicit drugs develop a tolerance quickly and will often escalate their dose. ${ }^{8}$ The tolerance to the hypnotic effects tends to develop more rapidly than to the anxiolytic effect, which occurs at a slower rate. ${ }^{16}$

The risk of physical and psychological dependence increases with frequent long-term, high-dose users. It is also higher in patients with a history of other drug abuse. ${ }^{8}$ Physical dependence is common in patients on longterm treatment, even at therapeutic dosages. ${ }^{13}$ Once physical dependence has developed, abrupt termination of treatment will be accompanied by withdrawal symptoms (Table 4). Many studies have shown that between 20 to $100 \%$ of patients taking BZD are physically dependent and will experience withdrawal symptoms upon abrupt discontinuation..$^{12}$ Some patients are going to experience withdrawal symptoms even with therapeutic doses, which may induce the prescription of higher doses. ${ }^{16}$ Individual risk factors for the development of dependence are not well understood but seem to include diagnosis of mental disease, male gender, younger age, low education level, being single or homeless, with a family history of substance abuse, being imprisoned and having antisocial personality disturbance. ${ }^{11,17}$ 


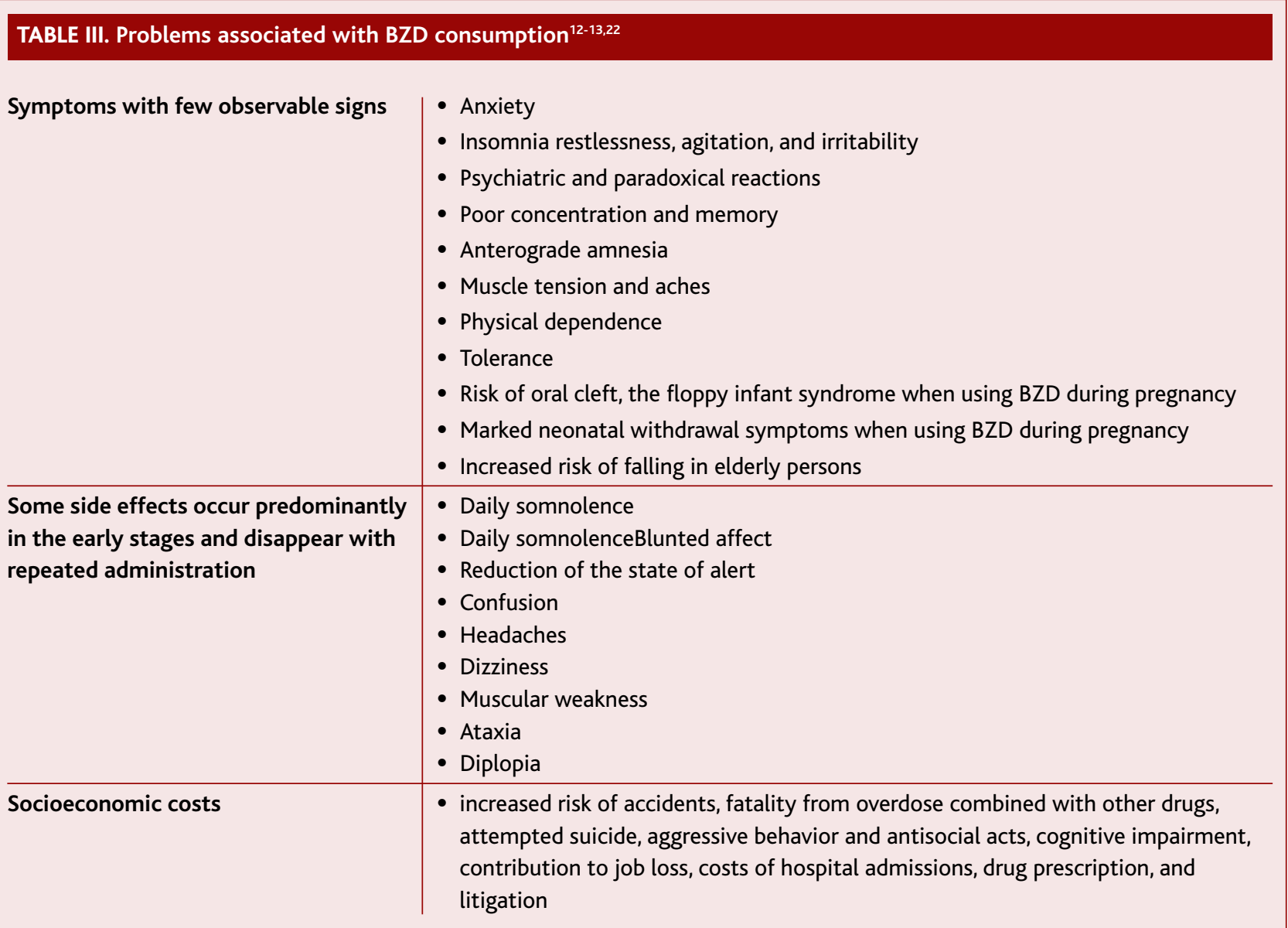

The risk of overdose when combined with other sedative substances such as alcohol, opioids, antipsychotics, and antidepressants must be taken into account, because of the central nervous system (CNS) depressant effect. $^{8}$

The elderly are more sensitive to the CNS effects of BZD, developing more frequently effects, like confusion, amnesia or ataxia. ${ }^{10}$ Short-acting BZD proved to be an independent risk for falls, which is higher as it is increased the risk of receiving a new prescription: number of physicians seen at baseline, being female, having a diagnosis of arthritis, depression or alcohol abuse..$^{13}$

\section{Overprescription of BZD}

The prevalent use of BZD represents a worldwide problem, despite their perceived favorable safety profile by both patients and doctors. ${ }^{12,16}$ It is estimated that only a third of BZD prescriptions in the elderly are considered appropriate. ${ }^{18}$ BZD are among the most common potentially inappropriate drugs for older persons, including NSAIDs, antihistamines, and antipsychotics. ${ }^{19}$ Some studies have pointed out reasons that lead to the use of BZD for longer periods than recommended:7,11,20

- Effectiveness in eliminating or reducing symptoms;

- Patients' fear of withdrawal symptoms;

- Patients' desire for rapid symptoms relieve puts more pressure on medical prescription;

- Difficult access to psychotherapy, which may indicate that this type of health care needs is not being met;

- Lack of patients' awareness regarding the risks of BZD use;

- «Medicalization» of human daily worries;

- The over-optimistic safety profile of BZD, also promoted by pharmaceutic industry (when first launched in the market in the '60s).

An inappropriate prescription may be prevented by 


\section{TABLE IV. Withdrawal symptoms and recommendations ${ }^{8,22}$}

Withdrawal symptoms can take almost any psychological and/or somatic form, but can be considered as falling into three main groups:

- Anxiety symptoms:

- Psychological: anxiety, panic attacks, poor memory, depression, paranoia, intrusive memories, cravings, nightmares, excitability, social and agoraphobia, obsessions, irritability;

- Physical: agitation, tremor, headache, weakness, dizziness, nausea, vomiting, diarrhea, constipation, palpitations, rashes, fatigue;

- Distorted perceptions: hypersensitivity to sound, light, touch, abnormal body sensations, depersonalization;

- Major incidents: fits, delirium (rare), hallucinations, psychosis (very rare).

\section{How to withdraw?}

Some health organizations, including the World Health Organization, propose a withdrawal schedule, in which the first step is to stabilize the patient on an equivalent dose of diazepam.

1. Calculate how much diazepam is equivalent to the daily dose of BZD that the patient currently uses.

2. The length of time between each dose reduction should be based on the presence and severity of withdrawal symptoms (the longer the interval between reductions, the more comfortable and safer the withdrawal). Generally, there should be at least one week between dose reductions.

3. It is not recommended to increase the dose when symptoms worsen; instead, persist with the current dose until symptoms abate, then continue with the dose reduction schedule.

4. Patients should be offered psychological care to address these symptoms.

simple intervention measures: ${ }^{10,21}$

- Careful selection of patients that benefit from BZD prescription;

- Clear definition of therapeutic goals;

- Frequent reconciliation of medication lists;

- Improvement of patients' knowledge about the benefits and risks of BZD use;

- Use of tools like electronic alerts and Beers' or STOP/START criteria, when considering the elderly population.

\section{- Withdrawing from BZD.}

BZD duration of action may affect the frequency and course of withdrawal. ${ }^{22}$ With short-acting BZD, the withdrawal symptoms typically begin one-two days after the last dose and continues for two-four weeks or longer. With long-acting BZD, the withdrawal may begin two-seven days after the last dose and continues for two-eight weeks or longer.

Many studies have been conducted in order to evaluate efficient measures to stop BZD long-term intake:

- The Eliminating Medications through Patient Ownership of End Results (EMPOWER) study in Canada found that an educational booklet about BZD resul- ted in drug cessation at six months in $27 \%$ of the patients versus $5 \%$ with usual care. The dose reduction was an additional $11 \%$ versus $6 \%$. This intervention also recommended discussing BZD use with a physician or pharmacist. ${ }^{23}$

- One meta-analysis showed that withdrawal interventions plus psychotherapy, prescribing interventions (e.g., medication review, consultation, or education) or multifaceted prescribing interventions, reduced the use of BZD when compared with control. Single-facet prescribing interventions and withdrawal interventions plus drug therapy did not reduce BZD use. The benefit of withdrawal interventions plus psychotherapy was maintained at three months of follow-up. ${ }^{11}$

- A systematic review found evidence for the efficacy of stepped care (minimal intervention followed by tapering off program) in discontinuing long-term BZD use. ${ }^{24}$

- Another review found evidence for a simple letter intervention. It showed to reduce long-term BZD usage in older patients with one cessation of BZD for every 12 letters sent. Despite the modest percentage, the minimal effort required suggests that it would have a high benefit-to-effort ratio. ${ }^{25}$ 
- One primary care multicenter study suggested that a structured and individualized intervention with a written plan for the gradual reduction of the dose is less time-consuming and as effective as more complex interventions with follow-up appointments. ${ }^{26}$ Another meta-analysis in the UK also concluded that a brief intervention with a flyer or a single consultation with the family doctor, for long-term users, are effective and efficient strategies to interrupt or reduce BZD, without adverse effects, with a necessary 12 contacts for one therapeutic cessation. ${ }^{25}$

- One study in a Portuguese health center showed a positive association between psychological support and lower BZD consumption, with lower costs and as an alternative to pharmacological intervention.? Another study concluded in favor of the benefit of combined intervention with group cognitive-behavioral therapy and reduction of dose in patients with insomnia and long-term treatments. Cessation of therapy was maintained after one year. ${ }^{27}$

In line with the above-mentioned results, it has been described that the success of discontinuing therapy in long-term users seems to be associated with the perception of self-efficacy, beliefs about withdrawal symptoms and initial motivation to quit. ${ }^{28}$ In fact, one study showed that patients choose to terminate consumption when they are well informed about the risks of BZD and when proposed a calendar for discontinuation..$^{23}$

It is also consensual that the safest way to manage BZD withdrawal is to gradually decrease the dose (Table 4). This helps to avoid or at least reduce withdrawal symptoms. ${ }^{13}$ The risk of withdrawal phenomena is higher after abrupt discontinuation of treatment because of the sudden decrease in $\gamma$-aminobutyric acid (GABA) signaling. ${ }^{8,29}$ Official guidelines in Portugal recommend that patients should be referred to intramural detoxification programs when using doses higher than 30 or $50 \mathrm{mg}$ of diazepam or equivalent on a daily basis. Reference should be considered in presence of antisocial personality disorder, history of seizures as a withdrawal symptom, previous unsuccessful regimens of detoxification, when it is the patient preference or in case of codependency of other drugs. ${ }^{10,30}$

\section{CONCLUSIONS}

Despite the well-established risks linked with long-term use, BZD continue to be widely prescribed and Portugal is one particular example of their high utilization rate.

BZD are remarkably useful drugs in short-term, occasional, or intermittent use. Adverse effects are recognized as significant risks in patients receiving treatment for longer than recommended. It is paramount to adopt strategies in order to prevent inadequate use of BZD, such as: cautious appraisal of the need for prescription, provision of educational information to the patient, use of the lowest dose possible and for the shortest time, assessment of efficacy in every consultation, and inclusion of information on gradually discontinuing the dose. Before prescribing, contraindications should always be considered and non-pharmacological or alternative pharmacological interventions should be envisaged. There are several guidelines recommending the use of other-than-BZD based therapies, including psychotherapy.

BZD discontinuation should be agreed by the doctor and patient. Structured approaches for long-term users, including brief intervention and engagement in gradual dose reduction programs, have shown good results, with additional benefit if associated with psychological support. ${ }^{31}$

Further research may help to better characterize predictive factors associated with BZD misuse, as well as to shed light on the impact of health programs aimed at helping long-term users to cease consumption at the primary care level.

\section{ACKNOWLEDGEMENTS}

The authors acknowledge the Calouste Gulbenkian Foundation, Regional Health Administration of Lisbon and Tagus Valley and the Health Centers group of Lisboa Norte, for the funding of the BEDS study, providing the context for this literature review.

\section{REFERENCES}

1. Pinto-Meza A, Moneta MV,Alonso J,Angermeyer MC, Bruffaerts R, Caldas-de-Almeida JM, et al. Social inequalities in mental health: results from the EU contribution to the World Mental Health Surveys Initiative. Soc Psychiatry Psychiatr Epidemiol. 2013;48(2):173-81.

2. Direção-Geral da Saúde. Portugal: saúde mental em números 2015. Lisboa: DGS; 2016.

3. Caldas-de-Almeida J, Xavier M, editors. Estudo epidemiológico nacional de saúde mental: $1^{\circ}$ relatório [Internet]. Lisboa: Faculdade de Ciências Médicas, Universidade Nova de Lisboa; 2013. Available from: http://www.fcm.unl.pt/main/alldoc/galeria_imagens/Relatorio_Estudo_Saude-Mental_2.pdf

4. Furtado C. Psicofármacos: evolução do consumo em Portugal Continental (2000-2012) [Internet]. Lisboa: INFARMED; 2014. Available from: 
http://www.infarmed.pt/documents/15786/17838/psicofarmacos_ relatorio $2013+\% 281 \% 29$.pdf/3e52568f-7f90-47c8-9903d128395c73e5

5. Cadilhe S. Benzodiazepinas: prevalência de prescrição e concordância com os motivos de consumo [Prevalence of prescription of benzodiazepines and concordance between doctors and patients reasons for their use]. Rev Port Clin Geral. 2004;20(2):193-202. Portuguese

6. Maria VA, Pimpão MV, Carvalho ML. Caracterização do consumo de benzodiazepinas em cuidados de saúde primários. Rev Port Clin Geral. 1994;11:99-114.

7. Furtado C, Teixeira I. Utilização de benzodiazepinas em Portugal continental (1999-2003) [Benzodiazepine's utilization in continental Portugal (1999-2003)]. Acta Med Port. 2006;19(3):239-46. Portuguese

8. Ford C, Law F. Guidance for the use and reduction of misuse of benzodiazepines and other hypnotics and anxiolytics in general practice [Internet]. Shropshire: SMMGP/FDAP; 2014. Available from: https://www.smmgp-fdap.org.uk/guidance-for-the-use-and-reductionof-misuse-of-benzodiazepines

9. Direção-Geral da Saúde. Tratamento sintomático da ansiedade e insónia com benzodiazepinas e fármacos análogos: norma n. ${ }^{\circ}$ 055/2011, de 27/10/2011, atualizada em 21/01/2015. Lisboa: DGS; 2015.

10. Eagles L. Guidance for prescribing and withdrawal of benzodiazepines \& hypnotics in general practice [Internet]. Aberdeen: NHS Grampian; 2008.Available from: https://www.benzo.org.uk/amisc/bzgrampian.pdf

11. Hinrichsen GA, Leipzig RM. Supervised withdrawal plus other interventions reduces benzodiazepine use in older persons. Ann Intern Med. 2014;161(6):JC2-3.

12. Ashton $\mathrm{CH}$. Benzodiazepines: how they work and how to withdraw. In: The Ashton manual [Internet]. Newcastle: Newcastle University; 2002. Available from: https://benzo.org.uk/manual/

13. Uzun S, Kozumplik $O$, Jakovljevi M, Sedi B. Side effects of treatment with benzodiazepines. Psychiatr Danub. 2010;22(1):90-3.

14. Gomm W, von Holt K, Thomé F, Broich K, Maier W, Weckbecker K, et al. Regular benzodiazepine and Z-substance use and risk of dementia: an analysis of German claims data. J Alzheimers Dis. 2016;54(2):801-8.

15. de Gage SB, Moride Y, Ducruet T, Kurth T, Verdoux H, Tournier M, et al. Benzodiazepine use and risk of Alzheimer's disease: case-control study. BMJ. 2014;349:g5205.

16. West LM. Benzodiazepines: benefits versus risks. J Malta Coll Pharm Pract. 2007;(13):24-6.

17. Drake RE, Mueser KT, Brunette MF. Management of persons with cooccurring severe mental illness and substance use disorder: program implications. World Psychiatry. 2007;6(3):131-6.

18. Dell'osso B, Lader M. Do benzodiazepines still deserve a major role in the treatment of psychiatric disorders? A critical reappraisal. Eur Psychiatry. 2013;28(1):7-20.

19. Lucchetti G, Lucchetti AL. Inappropriate prescribing in older persons: a systematic review of medications available in different criteria. Arch Gerontol Geriatr. 2017;68:55-61.

20. Janhsen K, Roser P, Hoffman K. The problems of long-term treatment with benzodiazepines and related substances. Dtsch Arztebl Int. 2015;112(1-2):1-7.

21. Soares MA, Fernandez-llimos F, Cabrita J, Morais J. Critérios de avaliação de prescrição de medicamentos potencialmente inapropriados: uma revisão sistemática [Tools to evaluate potentially inappropriate prescription in the elderly: a systematic review]. Acta Med Port. 2011;24(5):775-84. Portuguese

22. World Health Organization. Clinical guidelines for withdrawal management and treatment of drug dependence in closed settings. Geneva:WHO; 2009. ISBN 9789290614302

23. Tannenbaum C, Martin P, Tamblyn R, Benedetti A, Ahmed S. Reduction of inappropriate benzodiazepine prescriptions among older adults through direct patient education: the EMPOWER cluster randomized trial. JAMA Intern Med. 2014;174(6):890-8.

24. Voshaar RC, Couvée JE, van Balkom AJ, Mulder PG, Zitman FG. Strategies for discontinuing long-term benzodiazepine use: meta-analysis. $\mathrm{Br}$ J Psychiatry. 2006;189:213-20.

25. Mugunthan K, McGuire T, Glasziou P. Minimal interventions to decrease long-term use of benzodiazepines in primary care: a systematic review and meta-analysis. Br J Gen Pract. 2011;61(590):e573-8.

26. Vicens C, Bejarano F, Sempere E, Mateu C, Fiol F, Socias I, et al. Comparative efficacy of two interventions to discontinue long-term benzodiazepine use: cluster randomised controlled trial in primary care. $\mathrm{Br}$ J Psychiatry. 2014;204(6):471-9.

27. Baillargeon L, Landreville P, Verreault R, Beauchemin JP, Grégoire JP, Morin $\mathrm{CM}$. Discontinuation of benzodiazepines among older insomniac adults treated with cognitive-behavioural therapy combined with gradual tapering: a randomized trial. CMAJ. 2003;169(10):1015-20.

28. Ten Wolde GB, Dijkstra A, Van Empelen P, Neven AK, Zitman FG. Socialcognitive predictors of intended and actual benzodiazepine cessation among chronic benzodiazepine users. Addict Behav. 2008;33(9):1091-103.

29. Peng TJ, Patchett ND, Bernard SA. Takotsubo cardiomyopathy and catatonia in the setting of benzodiazepine withdrawal. Case Rep Cardiol. 2016;2016:ID8153487.

30. Department for Health and Ageing. Benzodiazepines: information for GPs [Internet]. Adelaide: Drug and Alcohol Services South Australia; 2013. Available from: https://www.sahealth.sa.gov.au/wps/wcm/connect/dbd6d500407749f193d6bb222b2948cf/Benzodiazepines++ GPs+2017.pdf?MOD=AJPERES\&CACHEID=ROOTWORKSPACEdbd6d500407749f193d6bb222b2948cf-mJJN4dC

31. Parr JM, Kavanagh DJ, Cahill L, Mitchell G, McD Young R. Effectiveness of current treatment approaches for benzodiazepine discontinuation: a meta-analysis. Addiction. 2009;104(1):13-24.

\section{FUNDING SOURCES}

Work conducting to this paper was in part supported by a research grant from Calouste Gulbenkian Foundation.

\section{CONFLICT OF INTERESTS}

The authors have no other conflicts of interest to declare.

\section{ENDEREÇO PARA CORRESPONDÊNCIA}

Joana Oliveira

E-mail: joanasaraoliveira@gmail.com

http://orcid.org/0000-0003-3027-5112

Recebido em 19-12-2017

Aceite para publicação em 04-11-2018 


\section{RESUMO}

\section{PRESCRIÇÃO E DESCONTINUAÇÃO DE BENZODIAZEPINAS EM CUIDADOS DE SAÚDE PRIMÁRIOS}

A utilização crónica de benzodiazepinas ansiolíticas ou hipnóticas é um tema controverso e visto como um problema de saúde pelos médicos de família.

Objectivos: Rever as indicações, efeitos adversos e riscos associados à sobreutilização de benzodiazepinas. São também exploradas algumas estratégias para a descontinuação destes fármacos em cuidados de saúde primários.

Métodos: Revisão bibliográfica com pesquisa estruturada na MEDLINE e outras publicações sobre o tema da prescrição e sobreutilização de benzodiazepinas, bem como protocolos de descontinuação relevantes para os cuidados de saúde primários.

Resultados e conclusões: Embora as recomendações nacionais e internacionais estejam alinhadas quanto às indicações e efeitos adversos das benzodiazepinas em utilização prolongada, estudos revelam uma sobreutilização preocupante destes fármacos em Portugal. As principais indicações das benzodiazepinas são a ansiedade e insónia em situações de doença grave, limitante ou que exponha o doente a elevados níveis de stress. O tratamento deve ser tão curto quanto possível, não ultrapassando as oito a doze semanas em casos de ansiedade e as quatro semanas nos casos de insónia. Existe evidência de bons resultados recorrendo a abordagens sistemáticas que incluam intervenções breves, acompanhadas da redução gradual da dose utilizada de benzodiazepinas. Esta revisão constitui o primeiro passo para o desenvolvimento, implementação e avaliação da efetividade de um programa de descontinuação gradual a ser disponibilizado aos médicos de família em Portugal.

Palavras-chave: Benzodiazepinas; Efeitos adversos; Cuidados de saúde primários. 